\title{
Site layout optimization for caisson structure fabrication
}

\author{
Changyoon Kim ${ }^{1}$, Taeil Park ${ }^{1}$, Sung Mo Ahn ${ }^{2}$, and Hyoungkwan Kim ${ }^{1} *$ \\ ${ }^{1}$ School of Civil and Environmental Engineering, Yonsei Unversity, Seoul, Korea \\ ${ }^{2}$ Civil Engineering Center, Marine and Port Team, SAMSUNG C\&T Corp., Seoul Korea \\ * Corresponding author (hyoungkwan@yonsei.ac.kr)
}

\begin{abstract}
Purpose As the volume of international trade increased, the needs for large concrete caisson breakwaters, which can accommodate the bigger vessels, increased accordingly. However, due to the size of the caissons, the constructions of large-scale maritime infrastructures often face challenges about how to manage the construction site, improve the construction processes, and enhance productivity. Method This paper presents a methodology to optimize the caisson structure fabrication process by controlling the locations of construction equipment and prefabrication facilities using genetic algorithm (GA), coupled with the functions of a Delmia-platform. First, a virtual construction site layout is established with a set of required facilities and equipment on the Delmia-platform based on the spatial information of the construction site. Site layout constraints and requirements are then determined to properly reflect the nature and conditions of the projects. Lastly, a genetic algorithm is employed to find out the optimal construction site layout for the construction processes. Results \& Discussion The proposed GA-based methodology is expected to assist construction engineers in determining optimized construction site layout for caisson structure prefabrication in the early project phase and further identifying the potential risks of projects.
\end{abstract}

Keywords: information technology, caisson, genetic algorithm, optimization, site layout

\section{INTRODUCTION}

A breakwater is one of the essential structures of a harbor that reduce the intense wave action in inshore water. To provide a safe harborage area for vessels, a breakwater should be designed to absorb the huge energy of the waves. A breakwater generally consists of large pieces of mass concrete components such as caisson structures which are produced by the following steps: 1) fabrication of base plate; 2) fabrication of caisson wall; 3) concrete curing. These steps are conducted in three different places to handle large amount of construction materials and equipment for improved productivity of the caisson fabrication processes.

Defining construction site layout is important task, because it has significant impacts on productivity of construction projects. For instance, construction time and cost can be increased due to the inappropriate location of facilities and other construction resources. In case of large and complex construction projects such as harbor construction projects, the negative impact of improper construction site layout tends to become stronger. The construction of large-scale maritime infrastructure is challenging due to the large-scale of caisson structures and limited space for the caisson structure fabrication factory in the construction site. A methodology is required to optimize site layout of the caisson structure fabrication for improved productivity of harbor construction projects.
Numerous studies have been conducted to develop methodologies for construction site layout optimization. Yeh ${ }^{1}$ utilized an annealed neural network to generate construction-site layout alternatives. Li and Love $^{2}$ developed a genetic algorithm (GA)-based site layout optimization method to deduce optimal location for site facilities. Hegazy and Elbeltagi ${ }^{3}$ developed a GA-based site layout planning model which is called "EVOSITE" to search for the optimum site layout. Azadivar and $\mathrm{Wang}^{4}$ developed a facility layout optimization method using simulation and GA. Osman et al. ${ }^{5}$ presented an automated hybrid system for layout planning of construction sites using a computer-aided design (CAD) and GA. Al-Hussein et al. ${ }^{6}$ developed optimization algorithm for selecting and locating mobile cranes on a construction site. Khalafallah and El-Rayes ${ }^{7}$ proposed a site optimization model to minimize hazard of wildlife attractants using a multi-objective GA. Zhang and Wang ${ }^{8}$ suggested a particle swarm optimization (PSO)-based methodology to solve construction site unequal-area layout problems. Easa and Hossain ${ }^{9}$ developed a noble mathematical optimization model for construction site layout using a concept of resource leveling. El-Rayes and Said ${ }^{10}$ proposed an approximate dynamic programming model to identify global optimal dynamic site layout plans. These previous studies showed that application of optimization algorithm to construction site layout problems could improve construction productivities. In particular, GA based 
optimization approach has advantages in identifying global optima by avoiding falling into local optima. This study utilized GA to identify optimized site layout for caisson structure fabrication processes.

The objective of this study was to develop a methodology to optimize the caisson structure fabrication process by determining the locations of construction equipment and prefabrication facilities using GA, coupled with the functions of Delmia platform. The following section provides a schematic idea about how to simulate optimal processes of construction project on Delmia platform. Then, the methodology of optimizing construction site layout using GA is presented using an illustrative example. Lastly conclusions and suggestions are followed.

\section{Construction Process Simulation}

Figure 1 shows a construction process simulation conducted on the Delmia platform to identify optimized construction processes of the project. This computer process simulation provides the detailed time and schedule information for the GA model development. For the model development, the processes of caisson structure fabrication and associated activities such as crane operation are first modeled. Resource usage and traveling frequencies between locations are then deduced by simulating and evaluating the construction process. Using the probability density functions of each activity, construction time and traveling frequencies are calculated on the computer simulation platform.

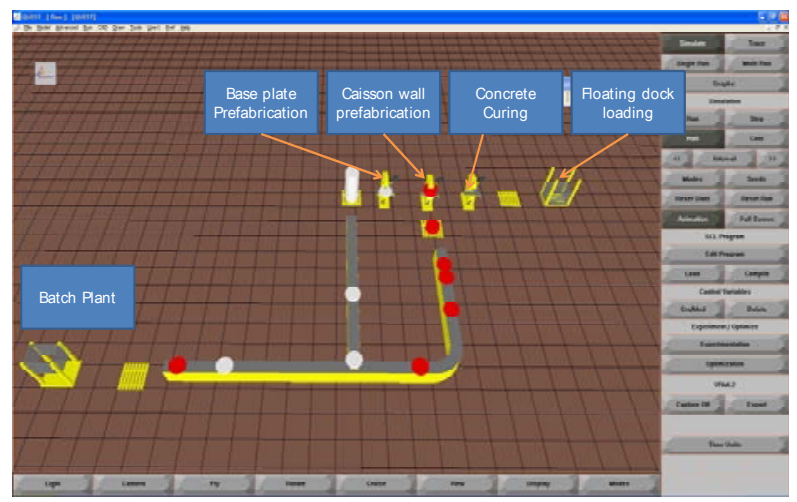

Fig. 1. Process simulation of caisson structure fabrication on the Delmia platform

\section{GA-based Construction Site Optimization}

\section{Site layout definition}

In this study, the construction site layout optimization is focused on how to properly allocate construction resources on predefined locations in construction site. Fig. 2 shows the predefined locations on the construction site. The predefined locations are represented as rectangles and the area of each rectangle is the same.
The objective function of optimizing site layout is to minimize the total traveling distance between locations ( $\mathrm{Li}$ and Love, 1998) ${ }^{2}$. The total traveling distance (TTD) is defined as eq. (1).

$$
\mathrm{TTD}=\sum_{i=1}^{n} \sum_{x=1}^{n} \sum_{j=1}^{n} l_{x i} f_{x i} d_{i j}
$$

where $n=$ number of facility locations, $I=$ location matrix variables, $f=$ traveling frequencies, $\mathrm{d}=$ distance between centers of two locations.

In this study, 9 facilities are defined as follows: 1 ) Steel plate storage; 2) Concrete mold storage; 3) Steel rod storage; 4) Concrete curing place; 5) Fabrication factory of caisson wall; 6) Prefabrication factory of base plate; 7) Steel rod factory; 8) Crane 1; and 9) Crane 2.

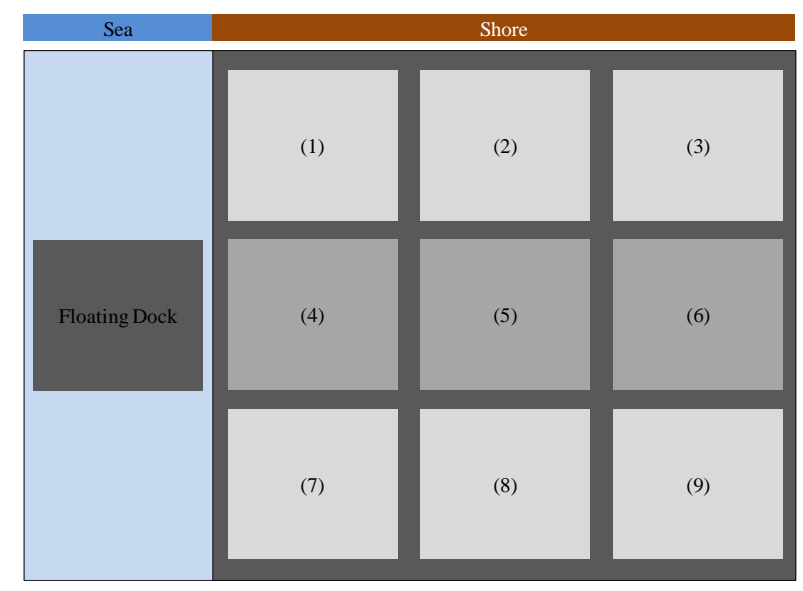

Fig. 2 Construction site layout

\section{Site layout optimization using GA}

The Genetic Algorithms (GA), proposed by Holland ${ }^{11}$, are heuristic search and optimization techniques that mimics the natural selection and biological evolutionary process. Unlike other optimization algorithms, GA has the capability of identifying global optima without falling into local optima. The GA model randomly searches for globally optimal solution which provides best fitness for objective function. In GA, a solution is represented as linear string called chromosome. A generation consisting of surviving individuals and new offspring is produced through reproduction mechanisms such as crossover, mutation, and selection of their parent's chromosomes.

The location of facilities can be represented as a string form, as shown in Table 1 (Li and Love, 1998) ${ }^{2}$. The position of each cell represents a facility location. For example, Table 2 indicates that facility 3 is location 2 in Fig. 2. The travel frequencies per day between facilities and the distances between the nine locations are defined as listed in Table 2 and Table 3 , respectively. 
Table 1. String layout representation

\begin{tabular}{|c|c|c|c|c|c|c|c|c|c|}
\hline Facility & 1 & 2 & 3 & 4 & 5 & 6 & 7 & 8 & 9 \\
\hline Location & 6 & 4 & 2 & 7 & 1 & 9 & 3 & 5 & 8 \\
\hline
\end{tabular}

Table 2. Traveling frequencies between two locations

\begin{tabular}{|c|c|c|c|c|c|c|c|c|c|}
\hline Location & 1 & 2 & 3 & 4 & 5 & 6 & 7 & 8 & 9 \\
\hline 1 & 0 & 5 & 2 & 2 & 1 & 1 & 4 & 1 & 2 \\
\hline 2 & 5 & 0 & 2 & 5 & 1 & 2 & 7 & 8 & 2 \\
\hline 3 & 2 & 2 & 0 & 7 & 4 & 12 & 9 & 4 & 5 \\
\hline 4 & 2 & 5 & 7 & 0 & 20 & 7 & 8 & 1 & 8 \\
\hline 5 & 1 & 1 & 4 & 20 & 0 & 30 & 4 & 10 & 3 \\
\hline 6 & 1 & 2 & 12 & 7 & 30 & 0 & 5 & 8 & 15 \\
\hline 7 & 4 & 7 & 9 & 8 & 4 & 5 & 0 & 7 & 6 \\
\hline 8 & 1 & 8 & 4 & 1 & 1 & 8 & 7 & 0 & 9 \\
\hline 9 & 2 & 2 & 5 & 8 & 3 & 15 & 6 & 9 & 0 \\
\hline
\end{tabular}

Table 3. Distance between two locations $(m)$

\begin{tabular}{|c|c|c|c|c|c|c|c|c|c|}
\hline Location & 1 & 2 & 3 & 4 & 5 & 6 & 7 & 8 & 9 \\
\hline 1 & 0 & 15 & 25 & 33 & 40 & 42 & 47 & 55 & 35 \\
\hline 2 & 15 & 0 & 10 & 18 & 25 & 27 & 32 & 42 & 50 \\
\hline 3 & 25 & 10 & 0 & 8 & 15 & 17 & 22 & 32 & 52 \\
\hline 4 & 33 & 18 & 8 & 0 & 7 & 9 & 14 & 24 & 44 \\
\hline 5 & 40 & 25 & 15 & 7 & 0 & 2 & 7 & 17 & 37 \\
\hline 6 & 42 & 27 & 17 & 9 & 2 & 0 & 5 & 15 & 35 \\
\hline 7 & 47 & 32 & 22 & 14 & 7 & 5 & 0 & 10 & 30 \\
\hline 8 & 55 & 42 & 32 & 24 & 17 & 15 & 10 & 0 & 20 \\
\hline 9 & 35 & 50 & 52 & 44 & 37 & 35 & 30 & 20 & 0 \\
\hline
\end{tabular}

Table 4. Best objective function values

\begin{tabular}{|c|c|c|c|c|}
\hline & $\begin{array}{c}\text { Population } \\
\text { size }\end{array}$ & Generation & $\begin{array}{c}\text { Mean } \\
(\mathrm{m})\end{array}$ & $\begin{array}{c}\text { Best } \\
\text { fitness } \\
\text { value } \\
(\mathrm{TTD})(\mathrm{m})\end{array}$ \\
\hline 1 & 25 & 100 & 1320.76 & 813 \\
\hline 2 & 50 & 100 & 890.48 & 814 \\
\hline 3 & 75 & 100 & 778.09 & 507 \\
\hline 4 & 100 & 100 & 579.46 & 444 \\
\hline 5 & 125 & 100 & 477.23 & 369 \\
\hline
\end{tabular}

\section{GA results}

To deduce optimal site layout solutions, the GA analysis was executed on a MATLAB platform. In this study, five levels of population sizes were chosen to investigate effects of population size on the performance of the GA system. Experiments with difference population sizes $(25,50,75,100$, and 125) were conducted under the probability value of crossover at 0.5 and the probability value of mutation at 0.01 . As shown in Figs. $3-7$, the GA system performed better when the population sizes are becoming bigger.

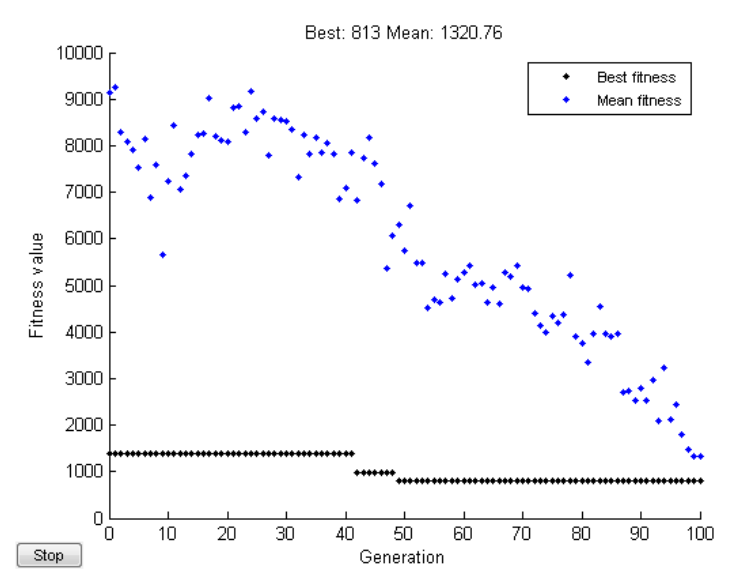

Fig. 3. Variation of objective function values (population size of 25)

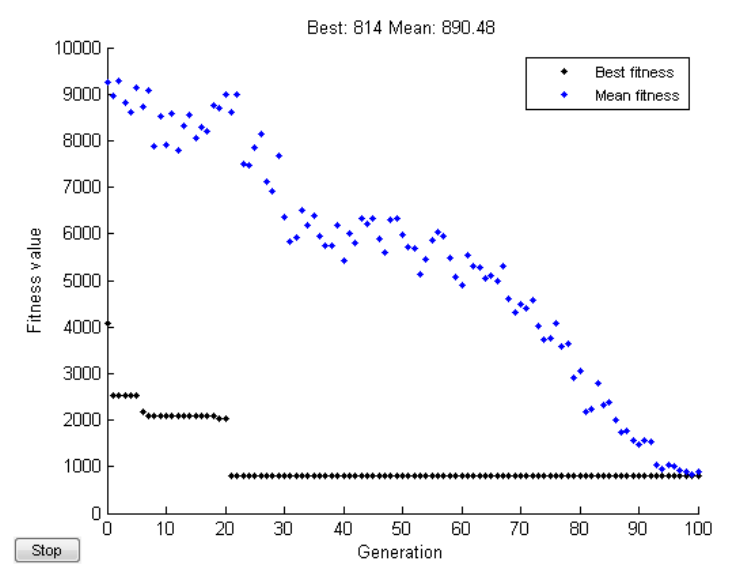

Fig. 4. Variation of objective function values (population size of 50)

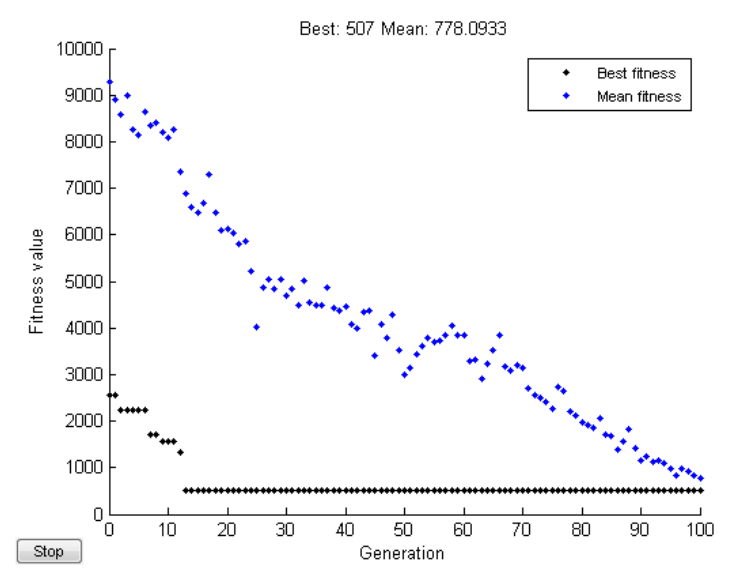

Fig. 5. Variation of objective function values (population size of 75) 


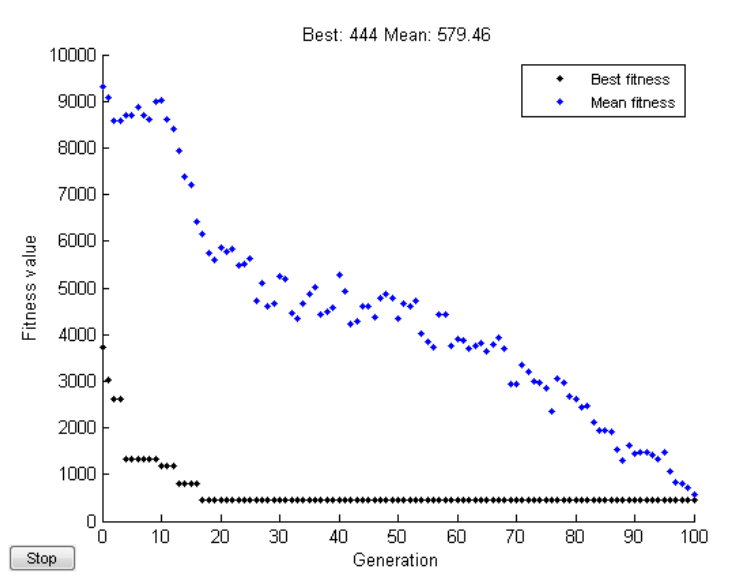

Fig. 6. Variation of objective function values (population size of 100)

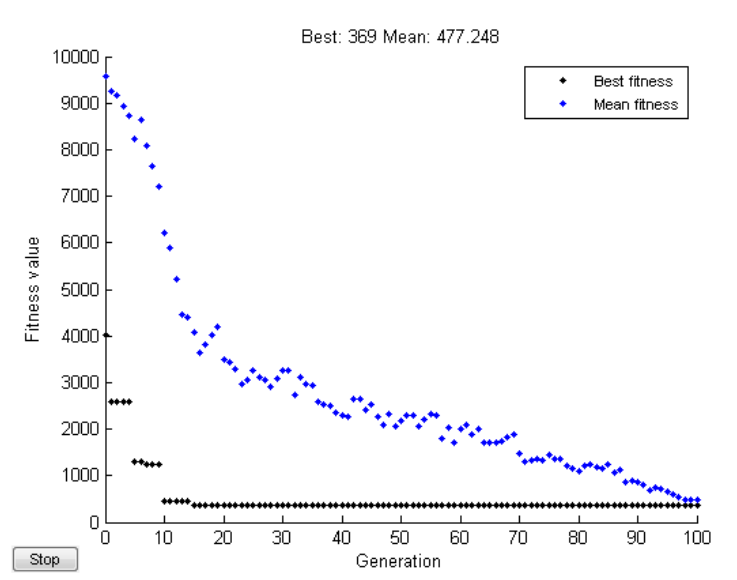

Fig. 7. Variation of objective function values (population size of 125)

The result of the population size 125 presented the lowest total traveling distance and the best fitness value. The optimal objective function value - minimization of total traveling distance - was $369 \mathrm{~m}$. The optimal site layout solution is presented in Table 4.

Table 4. Optimal construction site layout

\begin{tabular}{|c|c|c|c|c|c|c|c|c|c|}
\hline Facility & 1 & 2 & 3 & 4 & 5 & 6 & 7 & 8 & 9 \\
\hline Location & 1 & 5 & 3 & 4 & 2 & 6 & 7 & 8 & 9 \\
\hline
\end{tabular}

\section{CONCLUSIONS AND RECOMMENDATIONS}

This paper presented a methodology to optimize the caisson structure fabrication by determining the locations of construction equipment and prefabrication facilities. The proposed approach integrated computer simulation process and GA system for deducing optimal construction site layout. The simulation model for the construction projects enabled construction managers to effectively analyze and estimate process time and traveling frequency. The result of the process simulation provided reasonable input variables for developing the GA system.

Overall, the proposed GA-based methodology is expected to assist construction engineers in determining optimized construction site layout for caisson structure fabrication in early project phase. However, further study is required to improve the model, because the proposed model does not completely reflect the nature and conditions of construction site. Not only total traveling distance, but also interrelationship between facilities should be considered to improve the accuracy of the proposed model.

\section{ACKNOWLEDGMENTS}

This work was supported by a research fund from Engineering and Construction Group of Samsung C\&T Corp. This work was also supported by grants (2010-0014365 and 2011-0030841) from the National Research Foundation and Ministry of Education, Science, and Technology of Korea.

\section{References}

1. Yeh I-C., "Construction-Site Layout Using Annealed Neural Network", Journal of Computing in Civil Engineering, Vol. 9(3), pp.201-208, 1995.

2. Li, H. and Love, P.E.D., "Site-Level Facilities Layout Using Genetic Algorithms", Journal of Computing in Civil Engineering, Vol. 12(4), pp.227-231, 1998.

3. Hegazy, T. and Elbeltagi, E. "EvoSite: EvolutionBased Model for Site Layout Planning", Journal of Computing in Civil Engineering, Vol. 13(3), pp.198206, 1999.

4. Azadivar, F. and Wang, J., "Facility Layout Optimization Using Simulation and Genetic Algorithms", International Journal of Production Research, Vol. 38(17), pp. 4369-4383, 2000.

5. Osman, H. M., Georgy, M.E., and Ibrahim, M.E., "A Hybrid CAD-based Construction Site Layout Planning System using Genetic Algorithms", Automation in Construction, Vol. 12(6), pp. 749-764, 2003.

6. Al-Hussein, M., Alkass, S., and Moselhi, O., "Optimization Algorithm for Selection and on Site Location of Mobile Cranes", Journal of Construction Engineering Management, Vol. 131(5), pp. 579-590, 2005.

7. Khalafallah, A. and El-Rayes, K. "Optimizing Airport Construction Site Layouts to Minimize Wildlife Hazards", Journal of Management in Engineering, Vol. 22(4), 2006.

8. Zhang, H. and Wang, J. Y., "Particle Swarm Optimization for Construction Site Unequal-Area Layout", Journal of Construction Engineering Management, Vol. 134(9), pp.739-748, 2008.

9. Easa, S.M. and Hossain, K.M.A., "New Mathematical Optimization Model for Construction Site Layout", Journal of Construction Engineering Management, Vol. 134(8), pp.653-662, 2008.

10. El-Rayes, K. and Said, H., "Dynamic Site Layout Planning Using Approximate Dynamic Programming", Journal of Computing in Civil Engineering, Vol. 23(2), pp.119-127, 2009.

11. Holland, J.H., "Adaptation in Natural and Artificial Systems", Ann Arbor: The University of Michigan Press, 1975. 